Hydraulic Engineering Repository

Ein Service der Bundesanstalt für Wasserbau

Browne, Terence M.

Underwater Acoustic Imaging Devices for Portable Scour

Monitoring

Verfügbar unter / Available at:

https://hdl.handle.net/20.500.11970/100259

Vorgeschlagene Zitierweise / Suggested citation:

Browne, Terence M. (2010): Underwater Acoustic Imaging Devices for Portable Scour Monitoring. In: Burns, Susan E.; Bhatia, Shobha K.; Avila, Catherine M. C.; Hunt, Beatrice E. (Hg.): Proceedings 5th International Conference on Scour and Erosion (ICSE-5), November 7-10, 2010, San Francisco, USA. Reston, Va.: American Society of Civil Engineers. S. 931-940. 


\title{
Underwater Acoustic Imaging Devices for Portable Scour Monitoring
}

\author{
Terence M. Browne, P.E., M.ASCE
}

Collins Engineers, Inc., Phone (800) TEK-DIVE, E-mail: tbrowne@collinsengr.com

\begin{abstract}
Monitoring of key infrastructure below water and the channel bottom surrounding these items is essential for ensuring public safety and promoting longterm serviceability, as well as ensuring functional reliability of these waterway structures and the waterway natural resource.

New advances in underwater acoustic imaging have emerged as a tremendous portable tool for scour monitoring. Underwater acoustic imaging can provide photoquality visual images of submerged elements for structural inspection documentation; channel bottom elevation and material texture information for scour monitoring during flood events; spatial understanding for repair design activities; and construction observation for quality assurance documentation of scour countermeasure installations.

During hazardous flood conditions, hydrographic surveys and site evaluations by qualified underwater inspection divers to determine the maximum scour cannot always be performed due to safety reasons. When the scour depth is the deepest during a flood, this reliable portable sonar equipment can easily be used at numerous sites in an accurate, quick, and safe approach.
\end{abstract}

\section{INTRODUCTION}

The Federal Highway Administration (FHWA) requires that all highway bridges with a submerged substructure be inspected underwater to assess the structural integrity with certainty. Detecting and documenting any scour at a bridge site is a critical part of these inspections. Many owners of bridges and other infrastructure facilities are benefiting from underwater acoustic imaging by detecting and permanently capturing graphic depictions of scour depressions at a site, as well as documenting structure surface defects and erosion of submerged bank slopes.

During routine inspections as well as special scour assessments during floods, underwater acoustic imaging is now frequently used to detect and document scour so long as an inspector can access the waterway, or nearby bridge deck. If the distance from the bridge deck to the waterline is not excessive (generally considered less than ten feet), underwater acoustic imaging without other specialized equipment can be conducted from the bridge deck. Likewise, underwater acoustic imaging without a specially equipped larger vessel can be conducted from the waterway if the current is not excessive (generally considered less than 6 feet per second). For bridge deck freeboards greater than 10 feet or a waterway velocity greater than 6 feet per second, additional specialized equipment is required to deploy and maintain the sonar head in position. However, the vast majority of scour monitoring activities with underwater acoustic imaging can be conducted during a major flood by three individuals with lightweight equipment and a deployment system. Underwater acoustic imaging 
devices are portable, allowing data capture from any accessible area. Furthermore, data can even be obtained at some inaccessible areas caused by such conditions as debris or limited freeboard height under a bridge since the horizontal range of many sonar devices extend several hundred feet. While it is desirable to be located directly adjacent and above the imaged area to prevent shadows and distortion, useful data can still be obtained even when projecting at an angle due to obstructions.

\section{OVERVIEW OF UNDERWATER IMAGING}

Underwater imaging is a general concept that encompasses a wide variety of technologies. Underwater photography and underwater videography are the two most commonly used methods for obtaining underwater still images and underwater digital movies. However, water clarity greatly affects the quality of the images obtained by these two optical means. Furthermore, the camera range and lighting for underwater photography and videography often prohibit a large panoramic perspective, as well as only providing a two dimensional (2-D) perspective. Non-optical technologies that have demonstrated success in providing underwater images include sonar, laser, and radar. Laser scanning (often referred to as Lidar in above water applications) can produce extremely accurate underwater images, but light transmission factors related to water clarity and other limitations make it more widely used on offshore ocean structures than inland waterway bridges. Radar technologies, such as ground penetrating radar (GPR), can produce underwater images primarily of internal concrete defects or subsurface channel bottom geotechnical strata layers, while synthetic aperture radar (SAR) has been used to obtain large-area perspective underwater imaging of channel bottom topography.

Of all the non-optical underwater imaging technologies, sonar has demonstrated the most potential and is the most widely used in conjunction with scour monitoring. Even in the most turbid waters with zero visibility, sonar can provide data and images of the highest quality. Since sonar technology utilizes sound waves, it is also known as an acoustic technology. Underwater acoustic images vary in the quality resolution and dimensional perspective (2-D or 3-D) depending on the sonar device utilized. Sonar images with photo-quality resolution are referred to as high definition acoustic images. High definition acoustic images are most commonly obtained either with a 2-D perspective using sector scanning sonar, or with a 3-D perspective using multi-beam sonar. Both technologies will be discussed further in this paper.

Collins Engineers, Inc. has conducted research in conjunction with Queens University in Europe and Massachusetts DOT in the USA, to assert the usefulness of sonar technology related to bridge inspections and scour monitoring. These research studies have included comprehensive literature searches; synthesis of underwater inspection techniques nationwide as well internationally, and evaluation of data accuracy compared to diver inspections. FHWA will be conducting additional research in the United States to assess the use of sonar technology to inspect bridges especially where an underwater inspection by divers would be difficult or dangerous. FHWA will address any policy/guidance or regulatory issues regarding the use or substitution of sonar for underwater inspections by divers after their research is completed. Until then, bridge owners may use sonar technology to supplement 
bridge inspection diving operations (i.e., to document findings and help direct divers to areas of interest), and in situations where underwater inspections cannot be safely performed since some information is better than no information. However, sonar results alone are not currently a substitute for the data obtained by an underwater inspection performed by a qualified inspector with the appropriate intensity levels, as required by FHWA guidelines.

The Underwater Bridge Inspection manual published by the FHWA in 2010 outlines the various types, methods, and intensity levels associated with underwater inspections and scour monitoring. Therefore, this paper will only briefly touch on these aspects as they relate to underwater acoustic imaging, and will primarily focus on the applicability, advantages, and limitations of various sonar devices.

\section{SONAR DEVICES}

Sonar (originally an acronym for Sound Navigation and Ranging) uses transmitted and reflected underwater sound waves to detect submerged objects and measure distances. This technology is primarily used for water depth determination, underwater object detection, underwater communications, and underwater imaging. The sonar devices that are primarily used for underwater investigations are fathometers, multi-beam swath sonar, side-scan sonar, sector scanning sonar, lensbased multi-beam sonar, and sub-bottom profilers.

All sonar and radar devices operate on the simple principal of transmitting a wave toward an object to measure the time and amplitude of the reflected wave or echo. The waves are generated, emitted, and received from a transducer or antennae. The major differences between the various units are the frequency of the emitted wave, the method of focusing or directing the wave, and the display method. However, radar operates at a much higher frequency and is primarily used to evaluate subsurface observations; whereas, sonar is primarily used to obtain submerged surface data and images.

Wave frequencies can vary from sonic to radio frequencies; however, most are in the ultrasonic range. In general, low frequency waves will give lower resolution of objects but provide better penetration capabilities while the reverse is true for higher frequency waves. Most fathometers focus the waves into narrow cones of 20,40 , or 60 degrees depending on the transducer. Side-scan sonar flattens the cone into a fan shape. The scanning sonar uses a narrow beam which is progressively rotated to provide spherical coverage. The displays can vary from a single number, jagged lines, or near photographic quality depending on the amount of data gathered and processing methods used. Typically, time is converted to distance and amplitude is converted to either color or brightness. The amount of inspector interpretation is directly proportional to the quality and type of the displayed information. Therefore, it is important that the inspector understand how the unit works as well as the geometric relationship (perspective) of the transducer to the object of interest. Many times multiple perspectives make the task of display interpretation easier. The following paragraphs illustrate the various portable sonar devices that have been used for scour monitoring. 


\section{FATHOMETERS}

Water depths can be manually obtained with a sounding pole or lead line, but sonar devices provide more efficient and effective retrieval of electronic data. The simplest fathometers consist of an acoustic sending/receiving device (transducer) suspended in the water and a digital or paper recording device. The paper strip-chart recorder-previously used by recreational fishermen - has long ago been adapted for use as a data collection tool for hydraulic engineers and scour inspectors due to its permanent hard-copy documentation capability. However, these inexpensive stripchart recorders are being phased out by manufacturers and replaced by more modern survey-grade electronic precision echosounders, which work basically on the same principle and allow data collection on a digital memory card.

A fathometer works by emitting acoustic pulses through the water column toward the channel bottom by way of the transducer. The recording device measures the time it takes the pulse to reflect off the channel bottom and return to the transducer, and then converts that time into water depth. Fathometer frequencies typically range between $24 \mathrm{kHz}$ and $340 \mathrm{kHz}$, with higher frequencies yielding higher resolution, but little or no channel bottom penetration. As channel bottom penetration is typically not desired when performing a fathometer survey, a higher frequency is usually used (commonly $200 \mathrm{kHz}$ ). Many transducers currently available offer a variable beam angle. Using a larger beam angle covers a larger area of the channel bottom; however, as it is typically desired to get the best possible reading directly below the transducer, the smallest available beam angle is usually preferred. The inspector must exercise care to avoid mistaking an exposed bridge footing that might be undermined for the channel bottom being at a higher elevation. Such an error could occur if the sound wave was returned from a beam angle that captured the water depth to the top of the footing instead of recording the deeper adjacent true channel bottom elevation within the beam. Likewise, fathometers will not provide information about the channel bottom elevation located directly below a footing and cannot provide undermining dimensions in deep voids which is only possible by a diver probing under the footing.

More advanced fathometer systems include a global positioning system (GPS) receiver or robotic total station, which require significant training and expertise. When a fathometer is coupled with one of these devices, water depths can be postprocessed and referenced to a state plane or other horizontal coordinate system. This allows for very accurate channel bottom surveys, which can be easily compared to future surveys. When water conditions allow, a boat-mounted transducer allows efficient data collection. However, transducers mounted on poles, floats, or articulated arms have been used when maneuvering a boat during peak waterway flows is unfeasible.

The primary benefit of a fathometer is the ability to develop accurate channel bottom profiles. The profiles can be used to locate and quantify apparent scour depressions, areas of possible infilling, and channel bottom objects such as exposed pier footings or debris accumulation. Performing a fathometer survey prior to the diving inspection can direct the underwater inspector to potential problem areas on a bridge, as well as alert the inspector to potential below-water hazards. Overlaying and comparing channel bottom profiles from successive underwater bridge 
inspections can alert engineers to possible channel related problems. Bridge foundation information from as-built plans can be superimposed onto the channel cross-sections and profiles for easy reference purposes.

The primary limitation of a fathometer, or other traditional water depth sounding methods, is its inability to collect data outside the path of the vessel transporting the transducer. This limitation prevents detection of channel bottom irregularities or scour holes unless the vessel passes directly over the top of the area of interest with a narrow beam. A fathometer survey conducted during a typical underwater inspection for many state transportation agencies may include recording channel bottom profiles along the bridge fascias, as well as 100 feet and 200 feet upstream and downstream of the bridge. However, certain state DOTS, such as New York State DOT and Iowa DOT, obtain significantly more data for a highly detailed comprehensive hydrographic survey on certain waterways.

\section{MULTI-BEAM SWATH SONAR}

As mentioned previously, single beam echosounders are one of the most common forms of sonar used for scour monitoring applications. A single beam transducer is used to transmit and receive a series of sound waves to the benthic layer. The time lag between the transmission and reception is used to calculate the water depth to the point of first sound wave response. With this type of system, a single depth location is received and recorded. Single beam sonar is limited in that it does not have the ability to obtain 100 percent data coverage of the channel bottom as only one single point is returned to the transducer.

Multi-beam sonar systems, also referred to as swath echosounders, function as the name implies. This type of system uses a fanned array of sound beams that typically give 100 percent coverage of the seafloor or channel bottom. Different sound velocities and beam angles can be used to obtain required data. For instance, a typical multi-beam survey may have a fanned array that is capable of a "swath width" of seven times the water depth. This means that if the water depth is $100 \mathrm{ft}$ deep, bathymetric data can be obtained up to a swath of $700 \mathrm{ft}$ wide, or $350 \mathrm{ft}$ to the port or starboard side of the survey vessel. The accuracy of the outer edges tapers off to the outside of the fanned array, so it is good practice to have survey track lines overlap. The accuracy of multi-beam data is quite good if the system has been calibrated and proper sensors are used. Since the direction and angle of the beams can change with the heave, pitch, and roll of the survey vessel, it is necessary to have motion compensators and a gyrocompass that account (in real-time) for this motion and relay this information back to the on board processor. Calibration checks known as "patch tests" are also performed to calibrate the sensors and account for pitch offset, roll offset, and position time delay. These tests are performed prior to the survey using the appropriate software. Calibration tests are absolutely necessary to obtain quality data.

There are many advantages of using multi-beam sonar systems. Large areas of the seafloor or channel bottom can be mapped in an efficient manner. By using multiple or overlapping passes, the hydrographic surveyor is able to obtain 100 percent bottom coverage of the area. The shape and size of underwater anomalies or obstructions can be ascertained from this data. It also has a wide range of uses that 
include, but are not limited to, scour area monitoring, sea floor mapping, dredging support surveys, and channel obstruction detection and identification.

\section{SIDE-SCAN SONAR}

Commercial side-scan sonar was first introduced in the early 1960s and has been successfully used for documenting underwater findings for many years. Sidescan sonar works by emitting fan-shaped acoustic pulses through the water column perpendicular to the path of the transducer. The beam is narrow in the horizontal plane (typically less than 1 degree) and wide in the vertical plane (typically between 35 and 60 degrees). The resulting images from the channel bottom and objects located on the bottom or in the water column are representative of the echoed (backscattered) target intensity within the geometric coverage of the beam. When the images are stitched together along the direction of travel, they form a continuous image of the channel bottom and objects located on the bottom or in the water column. Side-scan sonar operating frequencies usually range between $83 \mathrm{kHz}$ and $800 \mathrm{kHz}$, with higher frequencies yielding better resolution, but less range. As an example, side-scan sonar with an operating frequency of $100 \mathrm{kHz}$ will typically have a range of up to 1,600 feet, while side-scan sonar with an operating frequency of 800 $\mathrm{kHz}$ will typically have a range of less than 250 feet. The transducer is either towed behind a boat or mounted on the transom or hull of the vessel.

The primary benefit of side-scan sonar is the ability to quickly and efficiently generate detailed images of large areas of the channel bottom regardless of water clarity showing channel bottom texture (sand, cobbles, riprap, etc.) and topography. It will also detect and depict exposed underwater members (footings, seals, piles, etc.), although some interpretation is required. Side-scan sonar can be used for many purposes, including delineation of exposed sediment and geologic formations, and detection of underwater debris or structure elements.

The primary limitation of side-scan sonar is the inability to generate detailed visual images of the vertical components of submerged structures. This is true even if the towfish transducers are rotated so the beams scan vertically through the water column. As a result, scanning or multi-beam sonar are better solutions for generating simple visual images of the vertical components of submerged structures. Other limitations of side-scan sonar include the inability to detect narrow linear targets parallel to the beams; difficulty keeping the towfish at a constant location behind the vessel and at a constant elevation in the water column; keeping the vessel along a consistent line at a constant speed; and vessel pitch and roll, especially if using a hullmounted application.

\section{SECTOR SCANNING SONAR}

The first known use of scanning sonar for a bridge assessment was performed by Collins Engineers, Inc. for the Washington DOT during the underwater inspection performed as part of the Lacey V. Murrow Floating Bridge failure investigation in 1991. Although scanning sonar was used to investigate submerged structures in the 1990s, it was not until circa 2000 that higher resolutions were available to produce photo-quality images. Since 2000 , numerous bridges and waterfront facilities have been scanned to document underwater conditions, as well as monitor scour 
depressions located near the infrastructure. Specialized underwater engineering firms, as well as government agencies, have found purchasing a sector scanning sonar device to be the best value with a relatively economical portable equipment cost with the highest tangible "photo-quality" 2-D image resolution available.

Scanning sonar works similarly to side-scan sonar in that the transducer emits fan-shaped acoustic pulses through the water. However, unlike side-scan sonar, which requires vessel movement to develop an image, the scanning sonar device works best when it remains stationary. The acoustic images are recorded in a series of slices generated by the rotation of the transducer. Computer software stitch these slices together to form a continuous image with vertical mosaic graphics or plan-view channel bottom profiles. Scanning sonar operating frequencies usually range between $330 \mathrm{kHz}$ and $2.25 \mathrm{MHz}$, with a common frequency used for channel bottom and structural imaging of $675 \mathrm{kHz}$. Although $675 \mathrm{kHz}$, which has a range of approximately $500 \mathrm{feet}$, is less than the side-scan sonar upper limit of $800 \mathrm{kHz}$, frequency is only one component of resolution. The ability to resolve a target is a combination of head stability, frequency, acoustic geometry, transducer beam width in the vertical and horizontal planes, pulse length, receiver bandwidth, signal to noise ratios, and target size, shape and acoustic impedance. As a result of the stable head, wide band width, narrow transverse beam widths, and small pulse length, images generated using scanning sonar are highly detailed even with an operating frequency of only $675 \mathrm{kHz}$.

The primary benefit of scanning sonar is the ability to produce highly detailed images of the channel bottom and vertical components of submerged structures regardless of water clarity. Scanning sonar can be used for many purposes, including detection and identification of scour depressions, areas of suspected infilling, exposed pier footings, debris accumulations, and some underwater structural deficiencies. Scanning sonar can also be used prior to and during diving operations to direct the underwater inspector to potential deficiencies and around potential below-water hazards. Near photo-quality images depicting entire or large portions of structure undermining due to scour can also be generated for inclusion into inspection reports and countermeasure design documents.

The primary limitation of scanning sonar is the inability to quickly and efficiently generate detailed images of large areas of the channel bottom. This is due to limited width range and the need for the sonar to be located close to the bottom in a stable position by way of a tripod or other deployment device for the highest quality. As a result, fathometers and multi-beam swath sonar devices are better solutions for overall channel bottom mapping of scour depressions, and side-scan sonar if searching for submerged objects over a large area in the objection. As developing highly detailed images using scanning sonar is heavily dependent on sonar positioning and stability, additional limitations may include lack of operator experience, difficult structure geometry, and excessive fast or rough waterways. Utilizing the right sonar device, or combination of sonar devices, for the exact situation and objections is critical.

So long as the acoustic image provides a clear, high definition visual of the substructure and channel bottom, many program managers feel it accomplishes a Level I inspection intensity, which allows the diving inspectors to verify any 
suspicious areas and focus on areas of concern, including Level II and Level III areas, as outlined by FHWA guidelines. The underwater acoustic images also provide a visual reference of the channel bottom elevations beyond hydrographic survey bathymetric contours.

\section{LENS-BASED MULTI-BEAM SONAR}

Lens-based multi-beam sonar is essentially scanning sonar that does not rotate. Scanning sonar consists of one beam that mechanically moves each transmit/receive cycle to create an image line by line. Lens-based multi-beam sonar consists of numerous beams placed side by side to create an image in one transmit/receive cycle. Many lens-based multi-beam sonar systems have manually selectable frequencies that allow for longer range for locating objects and higher resolution for investigating objects, as well as "heads-up" diver display capabilities with underwater monitor. Operating frequencies usually range between $0.7 \mathrm{MHz}$ and $1.8 \mathrm{MHz}$, with higher frequencies yielding better resolution, but less range. As an example, lens-based multi-beam sonar with an operating frequency of $0.7 \mathrm{MHz}$ will have lower resolution with a range of up to 240 feet, while lens-based multi-beam sonar with an operating frequency of $1.8 \mathrm{MHz}$ will have higher resolution with a range of less than 50 feet.

Similar to scanning sonar, the primary benefit of lens-based multi-beam sonar is the ability to produce images of the channel bottom and submerged structures regardless of water clarity. As lens-based multi-beam sonar provides real time images, it can produce near photo-quality videos, as opposed to simply near photoquality stills produced with scanning sonar. In addition, battery operated units with a mask-mounted display can be carried by an underwater inspector. Using such a unit, an underwater inspector can navigate to scour depressions and potential deficiencies, as well as around potential below-water hazards. The primary limitations of lensbased multi-beam sonar are range and clarity. Clarity decreases as the distance from the object increases. Also, the narrow range width makes overall observations difficult (such as evaluating large scour areas).

\section{GEOPHYSICAL SUB-BOTTOM SONAR PROFILERS}

High resolution sub-bottom profilers were first introduced in the mid-1960s and have been successfully used for defining sediment stratification and detecting bedrock. The surface component of the system generates images of the sediment stratifications, bedrock, and objects embedded in the channel bottom using either a digital or paper recording device.

The geophysical profiling systems can either be acoustic or electromagnetic radar. The electromagnetic radar system is referred to as ground penetrating radar (GPR). Radar waves are different than sonar waves. Two acoustic sub-bottom profiling systems are the tuned transducer operating between $2-15 \mathrm{kHz}$ and the CHIRP color sonar operating between $200 \mathrm{~Hz}-30 \mathrm{kHz}$.

The primary benefit of sub-bottom profilers is the ability to accurately locate sediment stratifications, bedrock, and objects embedded in the channel bottom. As a result, sub-bottom profilers are frequently used prior to marine structure construction or as part of a scour evaluation to detect infilling of depressions. With regard to 
underwater bridge inspection, sub-bottom profilers can be used to measure the true depth of scour depressions and locate embedded pier footings. Scour is most prevalent during a flood event; however, hazardous site conditions including complex flow patterns and the presence of drift and debris frequently prevent personnel from safely positioning instruments or diving during these events. After a flood event, the waterway current decreases and sediment is typically deposited into the scour depression. As the deposited sediment will typically consist of a different material or have a different density than the true channel bottom sediment, the sub-bottom profiler will depict the location of the previously undisturbed channel bottom.

The primary limitation of sub-bottom profilers is acoustic interference, which results in sub-bottom images that are more difficult to interpret. Acoustic interferences include multipath when operating in shallow water, and side lobes when operating near in-water structures. Multipath occurs when the transducer receives acoustic pulses that have reflected off the channel bottom, water surface, and channel bottom again. Side lobes occur when acoustic pulses encounter vertical objects, such as a bridge pier. As sub-bottom profilers use significantly lower operating frequencies than fathometers, the beam angles are typically much wider. As a result of these wider beam angles, collecting good quality sub-bottom images close to inwater structures is challenging.

\section{CONCLUSION}

Scour monitoring information can be obtained with several different techniques and displayed in a variety of documentation formats. Before the technology revolution, underwater inspectors during a site visit needed to measure individual depths by hand and manually record submerged channel bottom elevation data. Likewise, fixed methods could continuously record at one particular area on a site, but installation has proven expensive and maintenance intensive in many waterway situations. Therefore, portable sonar devices are the most commonly used method for monitoring channel bottom elevations and documenting of scour / bank erosion at site visits when deemed appropriate based on a written plan-of-action. FHWA policy requires a written plan-of-action be developed and followed for monitoring scour at all scour critical bridges and unknown foundation bridges. Figures 1 and 2 demonstrate the usefulness of underwater acoustic images.

As technology continues to improve, it is anticipated that the scour monitoring will continue to evolve with better data acquisition and display documentation. Scour that was extremely difficult to detect, or hazardous to document with divers in the past, can now be imaged to obtain measurements and photo-quality documentation. Human interaction still plays a vital part in evaluating scour depressions, and the engineer-diver's unique perspective is still needed, even with high-tech sonar devices to provide information such as channel bottom firmness, probe rod penetration data, and details on undermining beneath a foundation. 


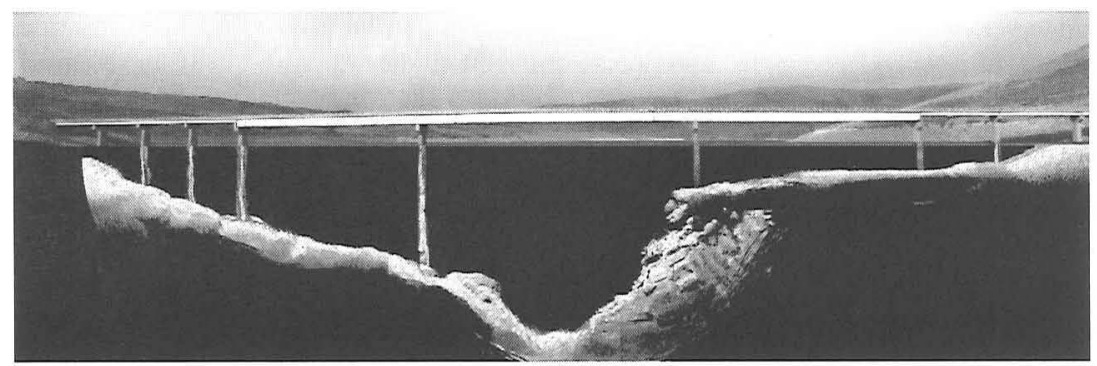

Figure 1: Scanning Sonar Image of Bridge Fascia and Channel Cross-Section.

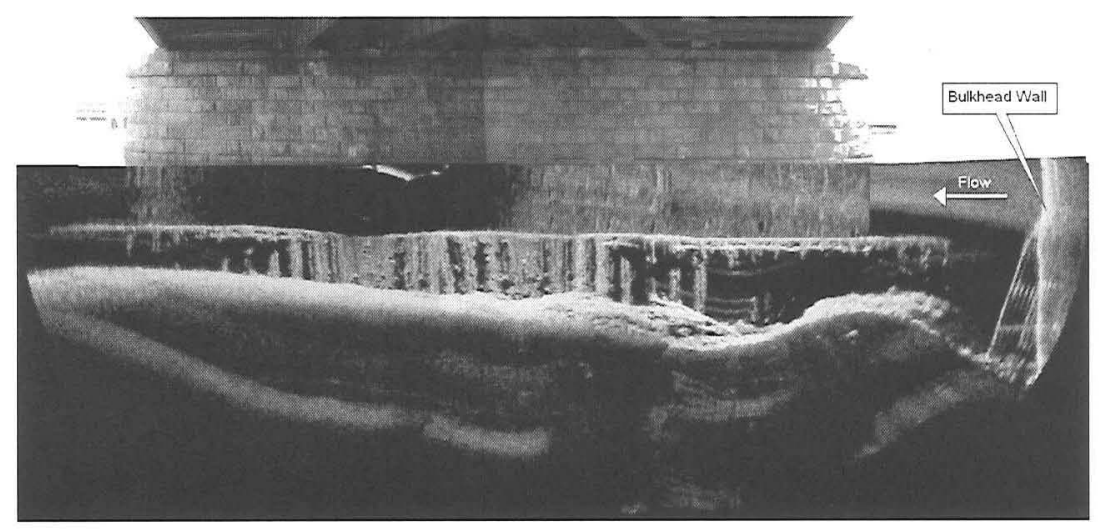

Figure 2: Scanning Sonar Image of Bridge Pier and Channel Bottom with Scour.

\section{REFERENCES:}

Browne, T., "Improvement of Underwater Bridge Inspection Documentation with Innovative Sonar Technology," FHWA Bridge Engineering Conference, 2010.

Browne, T. and Strock T., "Overview and Comparison of Nationwide Underwater Bridge Inspection Practices," TRB No. 2108 - Maintenance and Management of the Infrastructure, Journal of the Transportation Research Board, 2009.

Federal Highway Administration, Atlanta Technical Resource Center Memo by Cynthia Nurmi, 2009.

Federal Highway Administration, Underwater Bridge Inspection Manual, Publication No. FHWA-NHI-10-026, 2010. 